\title{
Bioequivalencia entre dos formulaciones de claritromicina comprimidos de liberación modificada existentes en el mercado chileno
}

\author{
LEONARDO GAETE G..$^{1}$, OSCAR SCHATLOFF B. ${ }^{2}$, FRANCO ANZIANI O. ${ }^{2}$, \\ CRISTIÁN SERRANO A. ${ }^{2}$, VERÓNICA CEBALLOS N. ${ }^{2}$, M. PIEDAD BELLO P. ${ }^{2}$, \\ MARIO ORTIZ O. ${ }^{1}$, IVÁN SAAVEDRA $S .{ }^{1}$ y YASUTARO YATABE R ${ }^{3 *}$
}

\section{Bioequivalence of two brands of clarithromycin in modified-release tablets available in the Chilean pharmacopeia}

A comparative bioavailability study was conducted in order to test the bioequivalence between two formulations of clarithromycin $500 \mathrm{mg}$ in tablets of modified release, a local formulation (Pre-Clar UD®), and the original product (Klaricid UD®). A microbiological assay was used to determine the antibiotic plasmatic concentrations. The assay is based on the correlation between the inhibition of bacterial growth in agar plates and the plasmatic concentration of clarithromycin. A total of sixteen non-smokers, healthy young volunteers participated and completed the study protocol which was approved by the local ethic committee. According to the guidelines recommended by the FDA and by means of our findings, we can assure that Pre-Clar UD ${ }^{\circledR}$ and Klaricid UD ${ }^{\circledR}$ are bioequivalents. Therefore, we may assume that both products are interchangeable without compromising clinical efficacy.

Key words: Clarithromycin; Pharmacokinetics; Bioequivalence.

\section{Introducción}

La biodisponibilidad de un fármaco es una medida de la cantidad y de la velocidad con que éste llega a la circulación sistémica ${ }^{1}$. Por su parte, la biodisponibilidad relativa o bioequivalencia es una medida comparativa de la calidad de una formulación farmacéutica, en donde se compara un producto nuevo (en términos de la velocidad y de la cantidad de principio activo que entrega) con el producto original (innovador del mercado). Conociendo la calidad de la formulación de un producto farmacéutico, el médico puede disponer de alternativas farmacéuticas, a distintos precios y sin comprometer la eficacia clínica ${ }^{2}$.

Por otra parte, la intercambiabilidad es el acto realizado por un médico de utilizar indistintamente una formulación u otra, disponiendo de ele- mentos de juicio suficientes para asegurar que la calidad de uno de los productos farmacéuticos es comparable o similar a la del otro (alternativas farmacéuticas) ${ }^{3}$.

El tipo de formulación con mayor variedad y la más utilizada es el comprimido, dada la facilidad de administración de principios activos, así como por la estabilidad de éstos. En este estudio se utilizaron comprimidos de liberación controlada, que proveen la dosis requerida en forma inmediata, seguida de una liberación gradual del fármaco en cantidad suficiente para mantener una respuesta terapéutica por un período de tiempo extendido $^{1}$, siendo este último dependiente de uno o más factores del tracto gastrointestinal.

La claritromicina es un antimicrobiano macrólido, derivado semisintético de la eritromicina. Difiere de ésta solamente en la metilación del

\footnotetext{
Programa de Farmacología Molecular y Clínica, ICBM, Facultad de Medicina, Universidad de Chile.

Estudiante de Medicina, Universidad de Chile.

Estudiante de Química y Farmacia, Pontificia Universidad Católica de Chile.

Parte de su Tesis desarrollada para optar al título de Químico Farmacéutico.
} 
grupo hidroxilo en posición 6 del anillo lactónico. Suele ser bacteriostática, pero se ha demostrado capacidad bactericida contra microorganismos muy sensibles cuando la concentración del antibiótico es elevada ${ }^{4}$.

$\mathrm{Su}$ biodisponibilidad es cercana al $60 \%$, alcanzándose la máxima concentración plasmática $\left(\mathrm{C}_{\text {máx }}\right)$ entre una y dos horas después de la administración oral. Entre el 20 y $40 \%$ de la dosis se excreta de forma inalterada en la orina y de 10 a un $15 \%$ como 14-hidroxi metabolito. La vida media de eliminación $\left(\mathrm{t}_{1 / 2}\right)$ es de 3 a 7 h y de 5 a $9 \mathrm{~h}$ para la 14-hidroxiclaritromicina, su principal metabolito ${ }^{8}$.

El objetivo del presente trabajo fue desarrollar un estudio de biodisponibilidad relativa después de administrar una dosis oral de claritromicina (500 mg) de dos formulaciones de liberación modificada disponibles en el mercado chileno. La formulación de referencia fue el producto original (Klaricid UD®) y el producto test fue una formulación similar conteniendo claritromicina (Pre-Clar UD®).

\section{Material y Métodos}

Voluntarios. En el estudio participaron 16 voluntarios varones sanos, cuyas características antropométricas se resumen en la Tabla 1.
Todos los voluntarios fueron informados apropiadamente sobre la metodología a emplear durante el estudio, la duración de éste, los fines que se perseguían, y los efectos adversos que podrían presentarse durante el desarrollo del mismo. Una vez informados, decidieron su participación en el estudio, mediante consentimiento informado. A los voluntarios seleccionados se les sometió a un completo examen físico por parte de un médico cirujano, y a un conjunto de pruebas de laboratorio, las cuales no mostraron desviaciones significativas que pudiesen indicar patologías renales, hepáticas, cardíacas o gastrointestinales. Una semana después de completado el estudio, los voluntarios fueron nuevamente sometidos a exámenes médicos y de laboratorio a fin de documentar su normalidad en relación al tratamiento recibido.

El protocolo del estudio fue aprobado por el Comité de Ética de la Facultad de Medicina de la Universidad de Chile. En todo momento se siguieron las recomendaciones para guiar los estudios en seres humanos, emanados de la declaración de Helsinki ${ }^{9}$.

Las formulaciones estudiadas correspondieron a: Klaricid UD®-producto B (Procedencia: ABBOTT Argentina SA., Registro ISP N ${ }^{\circ}$ 5654-B, lote $\mathrm{N}^{\circ}$ 531540-A), que fue considerado como producto referencia y Pre-Clar UD®-producto A (Laboratorio Chile SA, Registro ISP N ${ }^{\circ}$ B-0508/99,

Tabla 1. Características antropométricas de los voluntarios

\begin{tabular}{lccc}
\hline $\mathbf{N}^{\circ}$ & Edad (años) & Peso $(\mathbf{k g})$ & Talla $(\mathbf{c m})$ \\
\hline 1 & 20 & 89 & 180 \\
2 & 19 & 65 & 183 \\
3 & 25 & 77 & 168 \\
4 & 19 & 74 & 174 \\
5 & 25 & 65 & 168 \\
6 & 22 & 63 & 169 \\
7 & 21 & 78 & 167 \\
8 & 24 & 76 & 179 \\
9 & 25 & 70 & 180 \\
10 & 26 & 78 & 179 \\
11 & 20 & 71 & 168 \\
12 & 23 & 76 & 182 \\
13 & 18 & 59 & 163 \\
14 & 25 & 69 & 176 \\
15 & 22 & 72 & 180 \\
16 & 23 & 78 & 184 \\
Promedio & 22,3 & 71,6 & 175 \\
DS* & 2,6 & 7,4 & 6,8 \\
\hline
\end{tabular}

* DS: desviación estándar 
serie $\mathrm{N}^{\circ} 00028598$ ), que fue considerado como producto test. Ambos productos fueron adquiridos en locales de farmacia, al azar, y entregadas a un profesional ajeno al equipo de investigadores para que realizara el ciego. Los productos fueron devueltos, rotulados como A o B, de tal manera que ninguno de los investigadores ni los voluntarios pudieron saber a qué marca correspondían. La dosis administrada fue de $500 \mathrm{mg}$ de claritromicina como dosis única, que es la que contiene cada comprimido de liberación modificada (comprimidos UD). El diseño del estudio fue un doble ciego, randomizado, cruzado, de dos periodos ${ }^{3}$. El tiempo de depuramiento (wash out) entre los periodos fue de 7 días.

Los comprimidos de claritromicina fueron administrados en ayunas con $200 \mathrm{~mL}$ de agua potable. No se permitió la ingestión de alimentos hasta después de 2 horas de la administración. Los voluntarios permanecieron bajo observación en dependencias del Laboratorio de Farmacocinética durante las 24 horas post administración, en reposo relativo, siendo evaluados en forma continua por el equipo de investigación. Durante el transcurso del estudio, los voluntarios recibieron dietas estandarizadas y se les prohibió el consumo de café, alcohol y/o tabaco.

Las muestras sanguíneas de $10 \mathrm{~mL}$, se colectaron a tiempo 0 (pre-dosis), 2, 4, 6, 7, 8, 10, 12, $14,16,20$ y 24 horas post administración de la formulación. Las muestras fueron centrifugadas a $2.000 \mathrm{rpm}$ durante $10 \mathrm{~min}$ y el plasma se almacenó a $-20^{\circ} \mathrm{C}$ hasta el momento de su análisis. Una semana más tarde se repitió el procedimiento descrito, con la salvedad que se realizó el cruce de formulaciones, es decir, los voluntarios que recibieron la formulación A en el primer período, ahora recibían la formulación $\mathrm{B}$ y viceversa.

Determinación de claritromicina en el plasma. Para determinar las concentraciones de claritromicina en el plasma de los voluntarios se utilizó un ensayo o método microbiológico.

Esta metodología analítica se basa en cómo una determinada concentración de antimicrobiano afecta al crecimiento de un tipo de cepa bacteriana. El método microbiológico utilizado en el presente trabajo para la determinación de niveles plasmáticos corresponde al protocolo de Pollini et $\mathrm{al}^{10}$. Dicho método se basa en la medición de halos de inhibición de crecimiento bacteriano que se producen al colocar sensidiscos impregnados con plasma de los voluntarios que han recibido el antimicrobiano en un medio de cultivo (placa de Petri) que contiene una cepa bacteriana sensible a dicho antimicrobiano; en este caso particular la cepa utilizada fue Micrococcus luteus ATCC 9341. Este método ha sido validado y es ampliamente aceptado para determinar concentraciones de antimicrobianos en fluidos biológicos ${ }^{11,12}$. Así, para mayores concentraciones plasmáticas del antimicrobiano se producirá un halo de inhibición mayor, y para concentraciones menores un halo menor.

Con los datos de tamaño de inhibición del halo de crecimiento bacteriano, se puede obtener la concentración plasmática de claritromicina. Para ello, se confecciona una curva de calibración, la cual es una relación entre una concentración conocida del analito, en este caso el antimicrobiano, y la respuesta que se obtiene a esta concentración, es decir, el diámetro del halo de inhibición obtenido para esa concentración.

Análisis farmacocinético y estadístico. Los parámetros $\mathrm{C}_{\text {máx }}$ (concentración plasmática máxima) y $t_{\text {máx }}$ (tiempo al que se alcanza la $C_{\text {máx }}$ ) se obtuvieron mediante la inspección directa de las curvas de concentración plasmática versus tiempo. Los otros parámetros farmacocinéticos fueron determinados mediante el programa computacional AUC-RPP ${ }^{13}$, el cual se basa en un análisis de regresión de la fase terminal, del área bajo la curva $(\mathrm{ABC})$ y del área bajo la curva en el primer momento. A partir de estos parámetros son derivados el clearance total $\left(\mathrm{Cl}_{\mathrm{tot}}\right)$, la vida media de eliminación $\mathrm{t}_{1 / 2} \mathrm{y}$ el volumen de distribución aparente. Los valores de los parámetros $\mathrm{C}_{\text {máx }}$ y $\mathrm{ABC}$ obtenidos para ambas formulaciones se expresaron en forma logarítmica y fueron sometidos a análisis de varianza (ANOVA). Se determinaron intervalos de confianza del $95 \%$ para la diferencia entre los promedios de los parámetros farmacocinéticos obtenidos con ambas formulaciones. Se estimaron como significativas aquellas diferencias en las que el valor de $\mathrm{p}$ fue menor que $0,05^{14}$.

\section{Resultados}

Durante el desarrollo del estudio no se presentaron dificultades en la administración de los tratamientos, cumpliendo todos los voluntarios en forma satisfactoria con el protocolo establecido. No hubo contratiempos con ninguna de las muestras obtenidas, siendo por lo tanto, todas ella sometidas a posterior análisis.

La sensibilidad del método permitió detectar concentraciones desde $0,1 \mu \mathrm{g} / \mathrm{ml}$. Su variabilidad fluctuó entre 3 y 10\% para los estándares de concentración. El coeficiente de correlación en- 
tre el tamaño del halo de inhibición y la concentración del antimicrobiano fue de 0,96 (r).

La concentración máxima alcanzada con el producto A fue menor que la alcanzada con el producto B; sin embargo, al analizar la diferencia de sus promedios (sus valores expresados en forma logarítmica), se encuentra una $p=0,749$, lo que significa que esta diferencia no es estadísticamente significativa. En cuanto al parámetro $\mathrm{ABC}$ (área bajo la curva de concentración plasmática versus tiempo entre cero e infinito), los resultados tampoco mostraron diferencias significativas, con $\mathrm{p}=0,625$.

Respecto a los demás parámetros estudiados: volumen de distribución aparente $\mathrm{Vd}(\mathrm{p}=0,233)$, vida media de eliminación $\mathrm{t}_{1 / 2}(\mathrm{p}=0,323)$, constante de velocidad de absorción $\mathrm{K}_{\mathrm{abs}}(\mathrm{p}=0,096)$ y depuración corporal $\mathrm{Cl}(\mathrm{p}=0,815)$, las diferencias encontradas entre las dos formulaciones farmacéuticas no fueron estadísticamente significativas.

Además, se encontró que todos los parámetros farmacocinéticos están en concordancia con los descritos en otros estudios en que se utilizó dosis similares ${ }^{15}$.

La única diferencia estadísticamente significativa entre ambas formulaciones la presentó el valor $\mathrm{t}_{\text {máx }}(\mathrm{p}=0,046)$, siendo mayor para el producto B (6,12 horas contra 5,06 horas para el producto A), lo que indica que el tiempo en que se alcanza la concentración máxima con el producto A es significativamente menor que el requerido por el producto $\mathrm{B}$.
En la Tabla 2 se muestra un resumen de parámetros farmacocinéticos obtenidos y en la Figura 1 se muestran los perfiles plasmáticos comparativos para ambas formulaciones de claritromicina.

Es importante destacar que el perfil plasmático obtenido en este estudio para ambas formulaciones no corresponde al de una formulación de liberación inmediata, ni tampoco al producido por una formulación de liberación retardada o sostenida. Por lo tanto, los perfiles plasmáticos obtenidos permiten clasificar a ambas como formulaciones de liberación modificada. La forma más clara de constatar lo anterior es observar el valor de $\mathrm{t}_{\text {máx }}$, que en una formulación estándar fluctúa entre 1 y 2 horas y en el presente estudio fluctuó entre 5 y 6 horas.

\section{Discusión}

En este trabajo se realizó un estudio de biodisponibilidad relativa entre dos formulaciones farmacéuticas que contienen claritromicina. Para ello, a un mismo grupo de voluntarios sanos se les administró, en forma cruzada, una formulación que contiene $500 \mathrm{mg}$ de claritromicina como comprimidos de liberación modificada. El estudio de la bioequivalencia entre dos formulaciones farmacéuticas alude al concepto de la intercambiabilidad entre ellas. Los productos genéricos son, de acuerdo a la Organización Mundial de la salud, "productos farmacéuticos de múltiples orí-

Tabla 2. Parámetros farmacocinéticos promedio de claritromicina obtenidos con dos formulaciones de liberación modificada

\begin{tabular}{lrrrrc}
\hline Parámetro & \multicolumn{2}{c}{ Producto $\mathbf{A}$} & \multicolumn{2}{c}{ Producto B } & p \\
\hline $\mathrm{C}_{\text {máx }}(\mu \mathrm{g} / \mathrm{ml})$ & $1,46 \pm$ & 0,35 & $1,53 \pm$ & 0,43 & 0,749 \\
$\mathrm{t}_{\text {máx }}(\mathrm{h})$ & $5,06 \pm$ & 1,53 & $6,12 \pm$ & 1,36 & $0,046^{*}$ \\
$\mathrm{ABC}_{0 . \text { * }}((\mu \mathrm{g} / \mathrm{ml}) \mathrm{h})$ & $15,16 \pm$ & 2,82 & $16,26 \pm$ & 4,92 & 0,625 \\
$\mathrm{t}^{1 / 2}(\mathrm{~h})$ & $5,7 \pm$ & 1,11 & $5,3 \pm$ & 1,25 & 0,323 \\
$\mathrm{Vd}(\mathrm{L} / \mathrm{kg})$ & $3,92 \pm$ & 0,77 & $3,50 \pm$ & 1,13 & 0,233 \\
$\mathrm{~K}_{\text {abs }}(1 / \mathrm{h})$ & $1,60 \pm$ & 0,65 & $1,26 \pm$ & 0,42 & 0,096 \\
$\mathrm{Cl}(\mathrm{ml} / \mathrm{min})$ & $544,3 \pm 171,35$ & $558,56 \pm 170,79$ & 0,815 \\
\hline
\end{tabular}

$\mathrm{C}_{\text {máx }}=$ concentración plasmática máxima.

$\mathrm{t}_{\text {máx }}=$ tiempo requerido para alcanzar la $\mathrm{C}_{\text {máx }}$.

$\mathrm{ABC}_{0-¥}=$ área la bajo la curva concentraciones plasmáticas versus tiempo, desde cero a infinito.

$\mathrm{t} 1 / 2=$ tiempo de vida media.

$\mathrm{Vd}=$ volumen de distribución.

$\mathrm{K}_{\mathrm{abs}}=$ constante de velocidad de absorción

$\mathrm{Cl}=$ depuración del fármaco.

$(*)=$ significativamente diferentes 


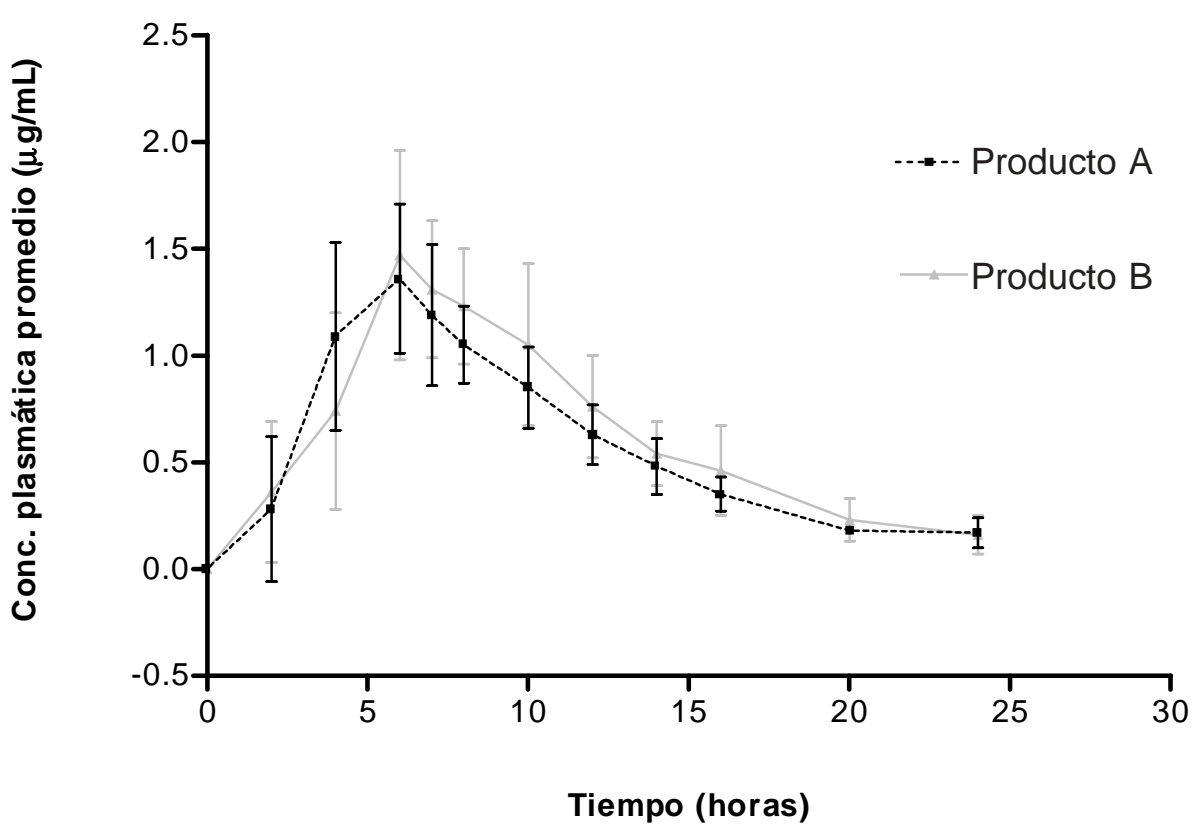

Figura 1. Concentraciónes plasmáticas promedio de claritromicina en 16 voluntarios sanos, obtenidas con dos formulaciones de liberación modificada. Los voluntarios recibieron en ayunas, un comprimido de $500 \mathrm{mg}$ de cada formulación. A los tiempos indicados se extrajeron muestras de sangre y se determinaron las concentraciones de claritromicina (ver métodos). Cada punto representa el promedio de tres determinaciones y la desviación estándar de la concentración plasmática en el tiempo.

genes intercambiables" 16 . Por ello, para fines de intercambiabilidad, una prueba de bioequivalencia con el producto innovador es indispensable.

La FDA recomienda que para establecer bioequivalencia entre dos productos no deben existir diferencias estadísticamente significativas entre sus promedios de $\mathrm{C}_{\text {máx }}$ y $\mathrm{ABC}$ expresados en forma logarítmica. El resto de las mediciones farmacocinéticas ayuda a la mejor caracterización de los productos a comparar, pero no determina la intercambiabilidad de los mismos. Es así por ejemplo, que en nuestro estudio la diferencia en $\mathrm{t}_{\text {máx }}$ resultó ser estadísticamente significativa $(\mathrm{p}=0,046)$ entre ambos productos. Este parámetro no es relevante para la FDA al momento de establecer bioequivalencia, ya que el tiempo en el que se alcanza la $\mathrm{C}_{\text {máx }}$ no tiene relevancia clínica al administrar formulaciones orales. Si lo que el clínico busca es alcanzar rápidamente altas concentraciones del fármaco en el plasma, debe preferir la vía parenteral para su administración.

Además la FDA recomienda que para estudios de bioequivalencia debe medirse solamente el fármaco parental y no el metabolito (claritromicina y 14-hidroxiclaritromicina en nuestro estudio). La base racional para esta recomendación es que el perfil de concentración versus tiempo del fármaco parental es más sensible a los cambios en la calidad de la formulación que la del metabolito, ya que éste refleja la capacidad de formación de él, su distribución y su eliminación. Se aceptan dos circunstancias en las cuales es preferible medir el metabolito: cuando la cantidad de fármaco parental sea mínimo, de forma tal que no exista una medición confiable de su concentración en el tiempo y en aquellos casos en que la producción del metabolito sea el resultado de una extensa metabolización en la pared intestinal o presistémico ${ }^{1}$. Ninguna de estas condiciones es aplicable en este estudio y por ello, no se incluyeron los datos de concentración plasmática de 14hidroxiclaritromicina para definir bioequivalencia.

Cuando se lanza un producto nuevo (innovador del mercado), éste debe documentar su biodisponibilidad, se solicita la incorporación en el grupo de estudio de hombres y mujeres en igual proporción, y que sean representativos de la población, abarcando un rango etario más amplio. Para los estudios de biodisponibilidad y bioequivalencia, las normas internacionales también recomiendan administrar los productos en ayunas $^{3}$. Con esto se evitan las alteraciones propias de la velocidad de vaciamiento gástrico, que 
introduciría una variable más al estudio. Para el caso de claritromicina, la presencia de alimentos retrasa la absorción del fármaco pero no modifica la extensión de éste ${ }^{8}$. En nuestro estudio se incluyó sólo a voluntarios jóvenes sanos, para disminuir al mínimo la variabilidad debido a la muestra. Esta práctica es ampliamente utilizada para los estudios de bioequivalencia ${ }^{1}$, ya que tal como se mencionó, permite disminuir la variabilidad y también los costos de este tipo de estudios. De esta forma, la variable "calidad de la formulación” de los dos productos de liberación modificada en estudio, fue analizada en voluntarios sanos bajo las mismas condiciones y en un grupo muy homogéneo.

Cuando dos productos farmacéuticos tienen una biodisponibilidad comparable, dentro de rangos muy definidos, se considera que ellos son bioequivalentes. De esto se deduce que son alternativas farmacéuticas intercambiables y bajo las recomendaciones de la comisión de medicamentos de la OMS, la copia debe recibir el nombre de producto genérico ${ }^{17}$.

En conclusión, los resultados aquí presentados señalan que el principio activo claritromicina, contenido en las formulaciones utilizadas en este estudio, se absorbe a velocidades y en magnitudes muy similares. De acuerdo a nuestros resultados y considerando aquellos parámetros farmacocinéticos que reflejan la cantidad de fármaco absorbido por el organismo, las formulaciones estudiadas son intercambiables.

Puesto que este estudio fue realizado en voluntarios sanos, no puede tomarse como evidencia para fundamentar la conveniencia de usar una u otra formulación con fines terapéuticos. La evidencia aquí presentada, señala claramente que con ambos productos se obtienen concentraciones plasmáticas y áreas bajo la curva comparables, y por lo tanto, pueden considerarse bioequivalentes. Dicho de otro modo, una vez iniciada la antibioterapia por el médico tratante con cualquiera de las formulaciones incluidas en este estudio, el profesional cuenta con elementos de farmacocinética que le permiten cambiar indistintamente una formulación por otra.

Finalmente, es necesario insistir en la necesidad de conocer la bioequivalencia de muchas formulaciones existentes en nuestro país, a fin de optimizar la terapia farmacológica.

\section{Resumen}

Se realizó un estudio de biodisponibilidad comparativa, para evaluar la bioequivalencia entre dos formulaciones de claritromicina de $500 \mathrm{mg}$ en comprimidos de liberación modificada, una nacional (Pre-Clar UD®), y el innovador del mercado (Klaricid UD®). Se utilizó un ensayo microbiológico para determinar las concentraciones plasmáticas del antimicrobiano. El ensayo está basado en la correlación entre la inhibición del crecimiento bacteriano y la concentración plasmática de claritromicina. Un total de 16 voluntarios, jóvenes sanos, no fumadores, participaron y completaron el protocolo del estudio, el cual fue aprobado por el Comité de Ética de la Facultad de Medicina de la Universidad de Chile. Los parámetros farmacocinéticos de: concentración plasmática máxima $\left(\mathrm{C}_{\text {máx }}\right)$, tiempo de vida media $\left(\mathrm{t}_{1 / 2}\right)$, área bajo la curva de concentraciones plasmáticas versus tiempo desde cero a infinito $\left(\mathrm{ABC}_{0-¥}\right)$, constante de velocidad de absorción $\left(\mathrm{K}_{\mathrm{abs}}\right)$, no mostraron diferencias estadísticamente significativas entre los productos utilizados. De acuerdo a los criterios recomendados por la FDA y en base a nuestros resultados, se concluye que las formulaciones Pre-Clar UD® y Klaricid UD® son bioequivalentes, asumiéndose que tendrían igual eficacia clínica.

\section{Bibliografía}

1.- FDA: Guidance for Industry. Bioavailability and bioequivalence studies for orally administered drug products - General Considerations. October 2000.

2.- FDA: Guidance for Industry. In vivo Bioequivalence Studies Based on Population and Individual Bioequivalenece Approaches. October 1997.

3.- FDA: Guidance for Industry. Average, Population, an Individual Approaches to Establishing Bioequivalence. August 1999.

4.- Kapusnik-ulner J, Sande M, Chambers H. Las bases farmacológicas de la terapéutica. Capítulo 47, novena edición 1996.

5.- Al-assi M, Ramirez F, Lew G, Genta R, Graham D. Clarithromycin, tetracycline, and bismuth: a new nonmetronidazole therapy for Helicobacter pylori infection. Am J Gastroenterol 1994; 89: 1203-5.

6.- CDC. Recommendations on prophylaxis and therapy for disseminated mycobacterium avium complex for adults and adolescents infected with human inmunodeficiency virus. 1993; 42: RR-9, 17-20.

7.- CDC. Sexually transmited diseases treatment guidelines. 1993 b; 42: RR-14, 1-102.

8.- Fraschini F, Scaglione F, Demartini G. Clarithromycin clinical pharmacokinetics. Clin Pharmacokinet 1993; 25: $189-204$.

9.- Declaracion de Helsinki. Documentos sobre ética médica, Colegio Médico de Chile AG; Grupos comunicacionales, 1986: 91-5.

10.- Pollini R, Lettieri B, Nanney M. Assay microbiological: clarithromycin in plasma- paper disc method. Protocolo $\mathrm{N}^{\circ}$ w96-124, ABBOTT Laboratories, Argentina 1996. 
11.- Coleman M R, Peloso J S, Moran J W. Microbiological plate assay for determination of tilmicosin in bovine serum. JAOAC Int 1995; 78: 659-62.

12.- Breier A R, García C V, Oppe T P, Steppe M, Schapoval E E. Microbiological assay for azithromycin in pharmaceutical formulations. J Pharm Biomed Anal 2002; 29: 957-61.

13.- Ritschell W. AUC-RPP basic computer program for compartment model independent pharmacokinetic analysis. Meth Find Exptl Clin Pharmacol 1986; 8: 633-40.

14.- FDA. Guidance Statistical Approaches to establishing Bioequivalence. February 2001.

15.- AHFS. Drug information. 1996; 231.

16.- Meredith P. Generic Drugs. Therapeutic Equivalence. Drug Saf 1996; 15: 233-42.

17.- Arias T. Glosario de Medicamentos $1^{\circ}$ edición OPS/ OMS, 1999.

\section{Correspondencia a:}

Leonardo Gaete $\mathrm{G}$

E-mail: lgaete@machi.med.uchile.cl 